\title{
Esfera pública e movimentos sociais: as possibilidades de atuação do Greenpeace no ciberespaço
}

\section{Public space and social movements: the action possibilities of Greenpeace in cyberspace}

\section{Rafaela Caetano Pinto ${ }^{[a]}$, Maria Ivete Trevisan Fossá ${ }^{[b]}$}

[a] Mestranda do Programa de Pós-Graduação em Comunicação da Universidade Federal de Santa Maria (UFSM), Santa Maria, RS - Brasil, e-mail: rafarpufsm@yahoo.com.br

[b] Doutora em Administração pela Universidade Federal do Rio Grande do Sul (UFRGS), atua nos programas de Pós-Graduação em Comunicação e em Administração da Universidade Federal de Santa Maria (UFSM), Santa Maria, RS - Brasil, e-mail: fossa@terra.com.br

\section{Resumo}

Este trabalho se propõe, por meio da descrição das tecnologias digitais utilizadas pelo Greenpeace, fazer apontamentos sobre a forma como os movimentos sociais estão se apropriando do ciberespaço para desenvolver suas atividades. Além disso, buscamos, através do modelo de circulação de poder político de Habermas, apontar como a organização Greenpeace influencia os centros decisórios. As possibilidades da internet permitiram a fragmentação do espaço público, tornando-o, assim, um não lugar difuso e multifacetado. Dessa forma, os movimentos sociais, apostam no uso da tecnologia da informação para obter visibilidade e conectar os defensores locais às questões globais.

Palavras-chave: Esfera pública. Movimentos sociais. Greenpeace.

\section{Abstract}

This work proposes - through the description of the tools used by Greenpeace - making notes about the means by which social movements are appropriating cyberspace to develop their activities. In addition to that, using Habermas' model of circulation of political power, we seek to bighlight how Greenpeace influences the decision-making centers. 
The possibilities brought by the internet allowed the fragmentation of the public space, making it a diffuse and multi-faceted non-place. This way, social movements have considered using information technology to get visibility and to connect local advocates to global issues.

Keywords: Public space. Social movements. Greenpeace.

\section{Introdução}

A esfera pública, ${ }^{1}$ problematizada primeiramente por Habermas, caracterizava-se por ser um espaço físico de debate, sendo que a palavra era restrita ao uso de algumas pessoas com direito a socializar os assuntos de interesse público. Habermas sofreu inúmeras críticas por suas teorias e, anos mais tarde, acabou revendo seus conceitos. A atualização de sua obra aconteceu graças às transformações sociais, políticas, culturais e tecnológicas que modificaram esse lugar físico em um ambiente não presencial de debates públicos.

Muitas foram as causas das transformações da esfera pública, mas é possível afirmar que a principal delas, a qual foi responsável pela descaracterização da conceituação de espaço físico, foram os meios de comunicação, principalmente a internet. Esta permitiu que a esfera pública se tornasse um ambiente fluído, multifacetado e interceptado por diversas vozes. Desse modo, a ambiência digital da internet possibilitou que diversos atores com direito restrito a fala pudessem dar visibilidade às suas pautas. Assim, muitos atores sociais, como os movimentos sociais, beneficiaram-se, pois, muitas vezes reprimidos pelos filtros midiáticos, não podem dar voz às suas reivindicações.

O Greenpeace, reconhecido mundialmente por sua atuação ambiental, também utiliza a internet com o intuito de pautar-se na esfera pública e conseguir visibilidade às suas ações, bem como mobilizar pessoas para os problemas ambientais. Ao apontarmos as possibilidades de atuação do Greenpeace no ciberespaço, inferimos que a organização, por meio de suas redes sociais, bem como dos espaços destinados aos públicos que se interessam em participar das mobilizações, buscam alargar a esfera pública por meio da internet. Esta possibilita a visibilidade das ações sociais, assim como conclama a participação dos públicos em prol da questão ambiental.

Baseados no modelo de circulação do poder político proposto por Habermas (1997 apud MARQUES, 2008), também apontamos a movimentação do Greenpeace enquanto ator periférico da esfera pública ao buscar mudanças em leis ou políticas criadas pelas instituições estabelecidas. Muitas vezes, a mudança política e social só pode ser realizada recorrendo-se às formas não ortodoxas de ações políticas. O Greenpeace, como exemplo de um movimento social não ortodoxo, promove o interesse comum pelo meio ambiente por meio de ações periféricas fora da esfera das instituições estabelecidas, ampliando, desse modo, a esfera pública. Dessa forma, o Greenpeace tenta chegar ao centro de decisão para pautar sua temática ambiental por meio de suas ações, tanto no âmbito virtual, quanto no físico.

\section{Antigos e novos apontamentos sobre a esfera pública e o modelo de circulação do poder político}

Anteriormente, o espaço público era compreendido como um espaço físico no qual algumas pessoas, com o poder de fala, podiam se manifestar a respeito de assuntos relevantes a toda sociedade. Hoje, esse conceito se aplica a um não lugar, assimétrico e fragmentado, em que os cidadãos coabitam e têm a emergência de se expressarem. Assim, existe um entrecruzamento de vozes que têm direito a fala e, dessa maneira, os temas sociais conseguem circular e se fazem presentes na sociedade contemporânea.

\footnotetext{
1 Nesse trabalho, os conceitos "esfera pública" e "espaço público" são tratados como sinônimos.
} 
Habermas (2003) analisa o avanço da mídia desde o início do séc. XVIII até os dias de hoje, traçando o surgimento e a queda da esfera pública. A esfera pública é uma arena de debates públicos na qual é possível discutir temas de interesse geral e formar opiniões. A esfera pública, segundo Habermas (2003), desenvolve-se primeiro nos salões e nos cafés de Londres, Paris e cidades europeias, sendo que os assuntos debatidos provinham de folhetos de notícias e de jornais, que recém começavam a aparecer. Mesmo contando com a participação de um número restrito de pessoas, Habermas (2003) afirma que os salões foram vitais na primeira fase da evolução da democracia. A esfera pública, neste período, envolve a reunião de indivíduos em situação de igualdade em um fórum para debate público e resolução de problemas políticos por meio da discussão pública.

No entanto, mesmo com o avanço dos meios de comunicação de massa, a evolução da esfera pública não se concretizou totalmente. Segundo Habermas (2003), a política é encenada no parlamento e na mídia, enquanto os interesses comerciais triunfam sobre os interesses do público. Desse modo, a opinião pública não é formada por meio de uma discussão racional aberta, mas a partir da manipulação e do controle (HABERMAS, 2003).

Embora criticado por muitos autores, não se pode falar no conceito de esfera pública sem referenciar o trabalho de Jürgen Habermas, uma vez que ele problematizou esse conceito para que fosse debatido posteriormente. Habermas (2003) fala a respeito da mudança na estrutura social da esfera pública e na mudança de sua função política. Assim, ele discute a interpenetração progressiva da esfera pública com o setor privado, pois a esfera pública burguesa é o resultado de uma tensão entre o Estado (setor público) e a sociedade civil (setor privado). Segundo Habermas (2003), há transferência dos deveres públicos para o poder social, o que acaba por banalizar a distinção entre o que é público e o que é privado. Portanto, o que se caracterizava por esfera pública burguesa se dissolve, porque a separação entre público e privado não fica esclarecida.

Para Habermas (2003), além da mudança na estrutura social da esfera pública, houve uma modificação na sua função política por meio da propaganda, que primeiramente possuía um cunho crítico e assumiu características de propaganda massiva. A propaganda, quando crítica, dava luz a temas que auxiliavam os indivíduos na formação de suas próprias opiniões. Além disso, segundo o autor, a publicidade possuía um princípio regulador das razões a serem compreendidas pelo público.

Habermas (2003) acreditava que os meios de comunicação eram responsáveis pela perda da faculdade crítica dos indivíduos e, consequentemente, pelo declínio da esfera pública. Isso graças à perda da função crítica dos meios de comunicação, que antes se preocupavam em fomentar o espaço de discussão por meio da exposição de razões e perspectivas, incitando o debate. Ao contrário, segundo Habermas (2003), os meios de comunicação foram pervertidos pelas lógicas da Indústria Cultural e do mercado, e passaram a ser um espaço de aclamação.

Isso também atingiu os jornais, que inicialmente se ocupavam em fomentar a opinião pública e seu espaço de discussão. Posteriormente, os próprios jornais construíam a opinião que não possuía característica pública, por não resultar da opinião de vários indivíduos, mas de alguns em particular, assim, passou-se de uma imprensa politizante para uma imprensa comercial. Essa mudança no cenário da imprensa, para Habermas (2003), acabou reduzindo o espaço da esfera pública, bem como a faculdade crítica do público.

Embora Habermas (2003) negasse o papel dos meios de comunicação, a importância desses atores na fragmentação da esfera pública foi estímulo para que o autor revisasse a sua obra e fizesse novos apontamentos, que contemplavam novos paradigmas e contextos. Segundo Marques (2008), ao pensar os meios de comunicação como instrumentos de reprodução e manutenção das relações de poder, Habermas entende atualmente os meios de comunicação como estruturas que articulam processos e atores nos procedimentos deliberativos, ao produzirem informações relevantes a estes.

Mas, ainda segundo Marques (2008), a crítica que Habermas faz a determinados filtros que permeiam o fazer jornalístico continua atual. Habermas (2003) acredita que, para fomentar o debate sobre determinados assuntos, os meios deveriam ter determinada autonomia. Isso acaba refletindo, por exemplo, na busca de meios alternativos para a divulgação de informações oriundas da periferia. Os meios, enquanto agentes que dão visibilidade aos assuntos que advém dos centros e 
das periferias, reorganizam os seus discursos por meio de alguns filtros que podem ser tanto ideológicos, quanto políticos ou econômicos. Segundo Marques (2008), Habermas denomina estes filtros como constrangimentos que podem ser de ordem tanto interna quanto externa.

Além da revisão do papel dos meios de comunicação na fragmentação da esfera pública, Habermas também buscou compreender o novo conceito desta. Para Mendes (2008), Habermas entende que o espaço público não se caracteriza como físico, assim como propunha antes, mas sob interações não presenciais permitidas pelos meios de comunicação. Nas palavras de Mendes (2008), Habermas acredita que a esfera pública serve para tematizar e problematizar os debates, a fim de que eles sejam tomados pelos parlamentos e por eles assumidos e elaborados.

Corroborando com o pensamento de Habermas, Lemos e Lévy (2010) atualizam o conceito de esfera pública por meio da internet. Para Lemos e Lévy (2010), as mídias digitais, juntamente com a globalização econômica e informacional, modificaram a sociedade e seu espaço, uma vez que este se tornou difuso e multifacetado, perdendo sua característica palpável de lugar. Essa reconfiguração modificou também o entendimento de espaço público, que anteriormente era dado como o ambiente físico de debate, e hoje ainda se mostra como um lugar de discussões, porém, desterritorializado.

Na segunda metade do século XX, os meios digitais ampliaram o espaço e possibilitaram a produção e distribuição de conteúdos, diferentemente das mídias de massa, colaborando, assim, para a ampliação da esfera pública. Além disso, a noção de espaço público também foi modificada, aquele espaço determinado pelas mídias massivas agora é atravessado por diversas vozes que estão na internet e têm liberdade de produzir e consumir conteúdos.

Segundo Marques (2008), a esfera pública se caracteriza como uma estrutura complexa, formada por arenas porosas que perpassam umas pelas outras. Desse modo, ela é constituída pela atividade comunicacional e pelos fluxos discursivos entre os atores envolvidos. A esfera pública se caracteriza por possuir horizontes abertos, permeáveis e deslocáveis (HABERMAS, 2003).
Marques (2008) faz uma ressalva ao modelo utilizado por Habermas (1997), que se refere a uma estrutura política e social e a circulação do poder político entre essas instâncias, ou seja, entre o centro e a periferia. No modelo de circulação do poder político, o centro seria formado por instituições formais, responsáveis pelas decisões; a seguir, estariam as instituições ligadas ao governo; e, no nível mais periférico, estariam as instituições que preenchem as necessidades sociais não supridas pelo Estado.

O nível periférico tem maior sensibilidade para a informação dos problemas sociais, mas sua contribuição se restringe a isso, pois não possui poder de decisão para modificá-la (FRASER, 1992 apud MARQUES, 2008). Ainda para esta autora, embora eles não tenham poder decisório, podem dar sugestões alternativas aos problemas, bem como informações importantes a respeito do cenário proposto. Porém alguns autores discordam de Habermas ao entenderem que ele subestima a participação pública no que tange essas decisões. Assim, entendemos que a esfera pública alternativa pode influenciar as decisões tomadas pela esfera pública dominante.

O novo pensamento de Habermas entende os meios de comunicação como agentes centrais nos fluxos comunicativos e deliberativos, ao invés de despolitizantes, ou seja, eles possuem a função de intermediar as demandas vindas dos atores centrais e periféricos para o processo de decisão. Marques (2008), parafraseando Habermas, diz que os meios de comunicação possuem centralidade nesse processo ao darem visibilidade às questões advindas dos diferentes atores, permitirem a simultaneidade de acesso aos conteúdos discutidos em diversos campos por uma ampla audiência e, também, por tornarem esses conteúdos acessíveis em qualquer espaço de tempo.

Os meios são arenas de debate em que há o entrecruzamento e o enfrentamento de pontos de vistas diferentes, mas não é democrático na visibilidade de todas as vozes. Além disso, Gomes (2007 apud MARQUES, 2008) fala dos inputs para temas que não teriam espaço para debates, assim os meios de comunicação tiram esses assuntos da invisibilidade, pois os meios são mediadores dos temas relevantes à sociedade civil (MARQUES, 2008). 


\section{Os movimentos sociais e sua atuação na ambiência digital}

As transformações socioeconômicas que ocorrem na sociedade provocam mazelas que afetam os indivíduos como um todo, de forma direta ou indireta. Assim, os indivíduos buscam soluções para seus problemas por meio de instituições, não ortodoxas e aqui se inserem os movimentos sociais. Para Henriques (2004, p. 61), os movimentos sociais se caracterizam como "ações coletivas orientadas para a mudança". O que é corroborado por Vizer (2007, p. 45), quando diz que é "uma forma de ação social que pretende justamente transformar as condições objetivas de seu ambiente".

Os movimentos sociais necessitam ter suas bases bem definidas, assim, pode-se conseguir maior envolvimento dos cidadãos, quando se tem claro quais são os seus objetivos. Conforme Castells (1999 apud HENRIQUES, 2004), os movimentos sociais necessitam deixar claro sua identidade e seu adversário, ou seja, o inimigo do movimento, e sua meta societal, ou seja, o horizonte proposto pelos seus objetivos.

Dentre as variadas classificações que existem a respeito dos movimentos sociais, ShererWarren (1999 apud HENRIQUES, 2004) faz três distinções entre eles: os contestadores, os solidarísticos e os propositivos. O primeiro tem objetivos de denúncia e protesto, já o segundo se caracteriza como movimentos de cooperação e parcerias buscadas para amenizar os problemas sociais, enquanto o último sugere proposições alternativas para o fim a que se propõe. O autor diz ainda que os movimentos podem ser híbridos quando apresentarem mais de uma das características citadas anteriormente.

As ações produzidas pelos movimentos sociais, bem como seus objetivos, necessitam ter visibilidade para que consigam ampliar suas bases de atuação. Para tanto, é necessário que os mesmos estejam visíveis nos espaços midiáticos. Para Henriques (2004, p. 18, grifos do autor),

os media adentraram o cenário das reivindicações sociais, alterando a maneira como os movimentos se apresentam, em decorrência das novas possibilidades de transmissão de informações, imagens e conhecimentos [...]. Os movimentos sociais, diante desse espaço mediatizado, procuraram transformar as lutas por reconhecimento em lutas por visibilidade.

Nesse contexto, a visibilidade se mostra importante às causas defendidas pelos movimentos sociais. Estas precisam ser reconhecidas publicamente para mobilizarem os cidadãos, que estão direta ou indiretamente envolvidos com o problema e que compartilham dos mesmos objetivos. Assim, Henriques (2004) defende o papel das mídias no reconhecimento dos movimentos sociais, pois ampliam sua visibilidade.

A fim de tornar visíveis os movimentos sociais, é importante a circulação de informações a respeito deles, uma vez que isso promove o sentimento de coletivização, conforme afirmam Toro e Werneck (2004). Assim, há um sentimento de pertencimento dos indivíduos envolvidos com o processo. Em um aspecto menos funcionalista da comunicação, é possível pensar sobre as relações que a comunicação pode estabelecer com os públicos envolvidos nesses movimentos. Assim, para o autor

compreendendo o caráter aberto dinâmico e descentralizado, desejável aos projetos mobilizadores, o fazer comunicativo, mais do que informar, toma por tarefa criar uma interação própria entre esses projetos e seus públicos, através do compartilhamento de sentidos e valores. Deseja-se, assim, que sejam fortalecidos os vínculos desses públicos com os movimentos e que sejam capazes de tornar iniciativas espontâneas de contribuir à causa dentro de suas especialidades e possibilidades (HENRIQUES, 2004, p. 39).

Podemos entender que a comunicação, ainda segundo esse autor, serve para gerar e manter vínculos. Dessa forma, além de informar a fim de conseguir mobilizar os cidadãos, a comunicação tem uma função mediadora entre os movimentos sociais e seus públicos. Além disso, ela coordena as ações sociais para que não sejam esparsas e desarticuladas com os objetivos dos movimentos (HENRIQUES, 2004).

A comunicação, de acordo com Henriques (2004), pode se caracterizar de três formas quando está relacionada aos movimentos sociais: dialógica, libertadora e educativa. A comunicação dialógica põe em relação sujeitos que discutem a respeito do 
assunto, aqui o saber não é imposto aos participantes dos movimentos; já a comunicação libertadora problematiza juntamente com o outro, de forma horizontal, a realidade dada a fim de entendê-la, explicá-la e modificá-la; a comunicação tem característica pedagógica porque reorganiza o repertório dos sujeitos que se encontram em interação.

Dentre os inúmeros meios que podem ser utilizados pelos movimentos sociais, até mesmo as mídias radicais, ${ }^{2}$ conforme a denominação de Downing (2002), a internet se caracteriza como um importante meio de comunicação entre os movimentos sociais e seus públicos. Para Vizer (2007), a internet também se caracteriza como uma mídia radical, essa ferramenta dá maior liberdade de produção de conteúdos pelo polo emissor e tangencia os filtros midiáticos - limites do que se é possível ser mostrado e dito (VIZER, 2007), ou os constrangimentos conforme denomina Habermas (2003).

Além da característica libertadora, a internet também promove o alargamento da esfera pública, contribuição bastante importante para os movimentos sociais que necessitam de um espaço de debate a fim de dar visibilidade às suas causas. Assim, como nas palavras de Gohn (2003), construir suas representações simbólicas por meio de seus discursos e práticas, que podem ser veiculados na internet, já que segundo Vizer (2007, p. 30), os “' [...] movimentos sociais [...] buscam reconhecimento e integração dentro dos espaços institucionalizados da sociedade".

O espaço público, além de ser ampliado pelos meios de comunicação e mais recentemente pela internet, também é estendido pelos próprios movimentos sociais, pois, segundo Alvarez et al. (2000 apud QUEVEDO, 2007, p. 30), eles “[...] criaram espaços públicos plurais, informais e descontínuos, onde pode ocorrer o reconhecimento dos outros como portadores de direitos". Ainda nas palavras desse autor, "[...] os movimentos sociais foram/são/ serão imprescindíveis à construção, aprofundamento e maturação da democracia (liberdade, igualdade, fraternidade, solidariedade), a partir das lutas pelos espaços, a criação de novos espaços, que se tornam arenas de discussão".

\section{As possibilidades de atuação do Greenpeace no ciberespaço}

A partir de informações contidas no site institucional do Greenpeace e tendo por suporte o modelo de circulação do poder político utilizado Habermas, apontamos de que forma o Greenpeace se apropria da internet a fim de perpassar os anéis porosos desse modelo de circulação proposto por Habermas (1997). Ao dar visibilidade às suas ações, o Greenpeace pretende mobilizar as pessoas com a causa da responsabilidade ambiental e afetar o centro decisório.

O Greenpeace ${ }^{3}$ atua em 43 países com o intuito de conscientizar as pessoas e as empresas a mudarem suas atitudes e promover a responsabilidade ambiental. A organização foi criada em uma ação desenvolvida por 12 pessoas, em 15 de setembro de 1971, em Vancouver, no Canadá. Especificamente no Brasil, a organização atua desde 26 de abril de 1990, sendo que seus escopos de trabalho no país são: Amazônia, Clima e Energia Renovável, Nuclear, Oceanos e Transgênicos.

Para atingir seu público e desenvolver ações que vão ao encontro do seu imaginário, hoje, o Greenpeace faz da internet um de seus principais meios de divulgação, embora já tenha se posicionado contra essa tecnologia, segundo Moraes (2001). Mas, considerando suas potencialidades, divulga as barbáries que agridem o meio ambiente no ciberespaço, ao passo que organiza ciberações, ou mesmo atos em ambientes físicos, sobre a conscientização ambiental.

2 Para Downing (2002, p. 33), a mídia radical define-se como "a forma mais atuante da audiência ativa expressa as tendências de oposição, abertas e veladas, nas culturas populares”.

Informações disponíveis em: <http://www.greenpeace.org/brasil>. Acesso em: 18 maio 2010. Fizemos contato via e-mail com a organização estudada, a fim de enriquecer a análise e utilizar dados extras aos dados dispostos no site, mas a resposta dada foi que o Greenpeace não fornece informações para pesquisas, além daquelas disponíveis em seu site institucional. 
A comunicação realizada pela organização é basicamente virtual, ${ }^{4}$ tanto que é disponibilizado um site com características de cada país em que ela atua, pois, além de se tratar de públicos distintos, o escopo de trabalho desenvolvido em um país não é o mesmo, variando de acordo com a demanda de cada lugar. O site do Greenpeace ${ }^{5}$ oferece diversas ferramentas que podem ser utilizadas pelos usuários a fim de acompanhar as notícias divulgadas, bem como suas campanhas. Entre essas ferramentas estão o Orkut, o Twitter, o Facebook, o Flickr, o YouTube, o seu $b \log _{,}{ }^{6}$ entre outros.

Todas essas ferramentas têm como objetivo divulgar as ações desenvolvidas pela organização, bem como mobilizar a participação de pessoas que se responsabilizem pela luta a favor da preservação do meio ambiente. Assim, segundo a afirmação de Toro e Werneck (2004), os processos de mobilização social devem informar os seus públicos para que os mesmos desenvolvam o sentimento de corresponsabilidade. Ao mesmo tempo, a comunicação deve possuir discursos sensíveis ${ }^{7}$ ao convocar os indivíduos para participarem das ações. Além disso, todos os escopos de trabalho do Greenpeace possuem objetivos bastante claros, o que de acordo com Toro e Werneck (2004), ajuda na participação das pessoas, por deixarem-nas seguras sobre os resultados que suas ações terão futuramente.

Como não poderia ser diferente, todo o movimento de mobilização buscado pelo Greenpeace ocorre no ciberespaço, lugar onde ele se apropria para falar aos seus públicos. Assim, ele convoca as pessoas para que ajudem no seu processo de alguma forma, seja como voluntário, colaborador ou ciberativista.
O ciberativista é convidado a participar pelo seguinte discurso da instituição: "Proteste nas 'ruas' da internet". ${ }^{8}$ Dessa maneira, o usuário pode, segundo a organização, fazer toda a diferença no desenvolvimento das ações que protegem o planeta ao tomar as seguintes atitudes: assinar as petições on-line; encaminhar os e-mails da instituição aos amigos; seguir o Greenpeace nas redes sociais; publicar suas notícias, vídeos, ou petições em blogs, sites e redes sociais; comentar as notícias; iniciar debates e fóruns sobre as campanhas do Greenpeace, incentivando a troca de conhecimento; tornar-se um colaborador. A partir desse discurso convocante, o Greenpeace ainda salienta que tudo isso reforça a mobilização na rede. ${ }^{?}$

Já o colaborador ${ }^{10}$ da organização ajuda com apoio financeiro, pois o Greenpeace não aceita doações de empresas, de governos ou mesmo de partidos políticos. Além disso, ele também participa das ciberações e das campanhas realizadas. $O$ voluntário é aquele que vai às ruas e participa das campanhas que se traduzem no ambiente físico, que se materializam, segundo Barbero (apud MORAES, 2001). Suas ações visam a atos não violentos e criativos que têm a finalidade de chamar a atenção das pessoas e das organizações sobre os impactos gerados ao meio ambiente.

Para participar do trabalho voluntário, ${ }^{11}$ que no Brasil é regulamentado pela lei 9.608, de 18 de fevereiro de 1998, é necessário que um formulário, disponibilizado no site, seja preenchido e enviado ao coordenador da respectiva cidade na qual o voluntário deseja atuar.Então, a pessoa participará de um processo seletivo, que varia sua regularidade de acordo com o

${ }^{4}$ Lembrando que além da internet, o Greenpeace busca a utilização de outros suportes, como a televisão, por exemplo, a fim de se comunicar com seus públicos.

Disponível em: <http://www.greenpeace.org/brasil>. Acesso em: 18 maio 2010.

${ }^{6}$ O site do Greenpeace e suas ferramentas estão aqui apenas sendo comentadas para que entendamos como é estruturada a comunicação principal dessa organização, a comunicação no ciberespaço, pois o intuito do trabalho não é analisar o seu site. Ademais não é necessário explicar o que é cada uma dessas ferramentas, pois já são redes sociais com funções conhecidas.

Exemplo retirado do site da organização: "Nós acreditamos que a mudança de atitudes individuais pode fazer uma grande diferença para o futuro do planeta. Juntos, nós podemos enfrentar os problemas e promover soluções”. Disponível em: < http://www. greenpeace.org/brasil>. Acesso em: 18 maio 2010.

8 Palavras retiradas do site. Disponível em: <http://www.greenpeace.org/brasil/pt/Participe/Ciberativista/>. Acesso em: 18 maio 2010.

${ }^{9}$ Palavras retiradas do site. Disponível em: <http://www.greenpeace.org/brasil>. Acesso em: 18 maio 2010.

${ }^{10}$ Informações disponíveis em: <http://www.greenpeace.org/brasil/pt/Participe/Colaborador/>. Acesso em: 18 maio 2010.

${ }^{11}$ Informações disponíveis em: <http://www.greenpeace.org/brasil/pt/Participe/Voluntario/>. Acesso em: 18 maio 2010. 
número de inscritos para o processo. Atualmente, o Greenpeace conta com 4.384 .000 ciberativistas e mais de 3.875.000 colaboradores no mundo todo, sendo que no Brasil ele soma mais de 250 voluntários, 47 mil colaboradores e 300 mil ciberativistas.

A partir dessas ferramentas utilizadas pelo Greenpeace, podemos apontar algumas formas de atuação da organização. Com o uso de redes sociais e de formas de participação do público que se identifica com a causa ambiental, podemos dizer que o Greenpeace se aproveita das possibilidades de alargamento da esfera pública pela internet com o intuito de mobilizar as pessoas. Enquanto movimento social tem a função de expandir o espaço público ao mesmo tempo em que busca aumentar sua rede de atuação e dar visibilidade às suas ações. Assim como suscita o debate sobre o tema, responsabilidade ambiental, que está em voga, sendo constantemente discutido pela sociedade.

Além disso, o Greenpeace, enquanto ator periférico, segundo a classificação de Habermas em seu modelo de circulação de poder político, busca, por meio da divulgação de suas ações e da mobilização, movimentar-se por entre os anéis porosos desse modelo, com o intuito de influenciar os centros de poder. As ações da organização, ${ }^{12}$ sejam elas virtuais ou mesmo reais, esperam resultados das instituições governamentais e empresariais, na busca de combater a devastação ambiental. Não podemos afirmar que elas têm esse poder, mas podemos inferir que, ao menos, são organizadas para esse propósito.

\section{Considerações finais}

Os movimentos sociais estão entre as mais poderosas formas de ação coletiva. Campanhas bem organizadas e persistentes podem gerar resultados impressionantes. Nos últimos anos, os ativistas ambientais venceram concessões importantes dos governos e das corporações, como no caso dos alimentos geneticamente modificados.
O avanço dos movimentos sociais é um reflexo dos riscos que afetam as sociedades humanas. Atualmente as instituições políticas democráticas cada vez mais se sentem acuadas de reagir criativamente às ameaças ao meio ambiente, aos perigos potenciais da energia nuclear e dos organismos geneticamente modificados.

Embora a confiança na política tradicional parece estar diminuindo, os movimentos sociais evidenciam que os cidadãos não estão desinteressados em relação à política. Observa-se que a inserção dos cidadãos e o apoio das pessoas às questões defendidas pelos movimentos sociais é uma forma de revitalização da democracia.

A tecnologia da informação, a serviço dos movimentos sociais, consegue unir em imensas redes regionais e internacionais ONGs, grupos religiosos, associações comunitárias, ativistas ambientais e outros que agem em defesa do interesse público. Segundo Castells (1999), cada movimento social depende dos meios de tecnologia da informação. A internet está na vanguarda do crescimento e proliferação dos movimentos sociais, embora não possamos esquecer os telefones celulares, máquinas de fax e a transmissão via satélite também na evolução dos movimentos na divulgação das causas sociais.

Os movimentos sociais ascenderam ao longo do tempo pelas mazelas sociais que atingem a população. Promovem um desenvolvimento de ações, que vão de encontro a esses problemas, em indivíduos mobilizados em torno de um objetivo comum. Habermas (2003) já problematizara essa tomada de funções do setor público pelo social como um fator negativo que influenciava a esfera pública burguesa.

Mas o que hoje alguns autores defendem é que os movimentos sociais têm uma função emancipadora e de defesa dos direitos dos indivíduos. Ademais, os movimentos sociais possuem muito mais do que uma função social, também podem ter uma função política. Segundo Habermas (1997 apud MARQUES, 2008), em seu modelo de circulação

\footnotetext{
${ }^{12}$ Exemplo retirado do site da organização para evidenciar a efetividade das ciberações e suas consequentes e interdependentes relações entre os atores envolvidos: Em 2006, o Greenpeace publicou o relatório "Comendo a Amazônia", detalhando como a demanda mundial por soja produzida na região alimenta a destruição da floresta. A rede McDonald's foi a primeira a responder à denúncia, eliminando a soja amazônica de sua cadeia de suprimentos. No mesmo ano, a campanha obteve uma conquista importante: a criação de uma moratória de dois anos na compra de soja proveniente de novos desmatamentos na Amazônia. Disponível em: <http://www.greenpeace.org/brasil>. Acesso em: 18 maio 2010.
} 
de poder político, existem anéis porosos que se interceptam, sendo que o poder de decisão vem do centro, então, a periferia não está habilitada para isso, embora tenha maior propriedade para falar sobre a realidade na qual está inserida. A verdade é que os movimentos sociais, com sua função política, são capazes de alargar a esfera pública enquanto espaço de debate de assuntos de interesse coletivo.

A esfera pública, conceituada por Habermas (2003), sofreu alterações em seu conceito ao longo do tempo. Anteriormente, era entendida como espaço físico de debate privilegiado a algumas vozes habilitadas a expor os assuntos relevantes a toda população. Hoje, é entendida como um não lugar, multifacetado e difuso, que pode ser interceptado por diversos atores, até mesmo os movimentos sociais.

Embora desconsiderados anteriormente por Habermas, os meios de comunicação possuem um papel fundamental nesse cenário. Eles foram capazes de modificar a estrutura e o conceito do que se entendia por esfera pública. Dentre eles, destaca-se a internet, pois transformou o espaço público (LEMOS; LÉVY, 2010), agora, com características desterritorializadas, assimétricas, fragmentadas e plurais. Ademais, a internet é capaz de institucionalizar os discursos dos atores sociais por tangenciar os filtros das mídias tradicionais.

Então, por meio do site institucional do Greenpeace, buscamos fazer alguns apontamentos a respeito das ferramentas utilizadas pela organização no ciberespaço. Assim como assinalamos possibilidades relacionadas com as ferramentas utilizadas pela organização e sua ligação com o modelo de circulação de poder político proposto por Habermas (1997, apud MARQUES, 2008). Por meio de suas redes sociais e de ferramentas para participação do público, podemos inferir que o Greenpeace utiliza o alargamento da esfera pública, possibilitada por esse meio, para mobilizar seus públicos, bem como desenvolver seu papel político, de ator que proporciona a interceptação da esfera pública por diversas vozes e a torna fluida.

Também podemos entender que, por meio da visibilidade de suas práticas e discursos, a organização perpassa os anéis porosos do modelo indicado por Habermas. Enquanto instituição, o Greenpeace encontra-se no anel mais periférico do modelo, por conhecer mais a realidade em que está inserida e a qual defende, o meio ambiente, ou seja, é um ator social legitimado a falar a respeito. Assim, podemos dizer que ele tem empoderamento para influenciar os anéis restantes, o intermediário e o central, na tomada de decisão. Talvez as ações de mobilização realizadas pelo Greenpeace não tenham tal poder dentro desse âmbito, mas, de qualquer forma, pautam esse tema e lhe dão visibilidade para tentar articular esse processo.

\section{Referências}

BRASIL. Presidente da República. Lei n. 9.608, de 18 de fevereiro de 1998. Dispõe sobre o serviço voluntário e dá outras providências. Diário Oficial [da] República Federativa do Brasil, Poder Legislativo, Brasília, DF, 23 dez. 1996. p. 27833. Disponível em: < http://www.planalto. gov.br/ccivil_03/leis/L9608.htm>.Acesso em:23 jul.2010.

CASTELLS, M. A sociedade em rede. São Paulo: Paz e Terra, 1999.

DOWNING, J. D. H. Mídia radical: rebeldia nas comunicações e movimentos sociais. São Paulo: SENAC São Paulo, 2002.

GOHN, M. da G. Movimentos sociais na atualidade: manifestações e categorias analíticas. In: GOHN, M. da G. (Org.). Movimentos sociais no início do século XXI: antigos e novos atores sociais. Petrópolis: Vozes, 2003. p. 13-32.

HABERMAS, J. Direito e democracia: entre facticidade e validade. Tradução de Flávio Beno Siebeneichler. Rio de Janeiro: Tempo Brasileiro, 1997.

HABERMAS, J. Mudança estrutural na esfera política: investigações quanto a uma categoria de sociedade burguesa. 2. ed. Rio de Janeiro: Tempo Brasileiro, 2003.

HENRIQUES, M.S. (Org.). Comunicação e estratégias de mobilização social. Belo Horizonte: Autêntica, 2004.

LEMOS, A.; LÉVY, P. O futuro da internet: em direção a uma ciberdemocracia. São Paulo: Paulus, 2010.

MARQUES, Â. C. S. Os meios de comunicação na esfera pública: novas perspectivas para as articulações entre diferentes arenas e atores. Revista Líbero, São Paulo, v. 11, n. 21, p. 23-36, 2008. 
MENDES, S. da R. A esfera pública. In: MENDES, S. da R. Esfera pública e direitos fundamentais: estudos sobre a liberdade de comunicação. Passo Fundo: Instituto Superior de Filosofia Berthier, 2008. p. 23-38.

MORAES, D. de. O concreto e o virtual: mídia, cultura e tecnologia. Rio de Janeiro: DP\&A, 2001.

QUEVEDO,J.A perspectiva de comunicação na América Latina a partir de seus movimentos sociais como possibilidade de percepção da integração. In: QUEVEDO, J.; IOKOI, Z. M. G. (Org.). Movimentos sociais na América Latina: desafios teóricos em tempo de globalização. Santa Maria: MILA; CCSH; Universidade Federal de Santa Maria, 2007. p. 26-48.
TORO, J. B. A.; WERNECK, N. M. D. Mobilização social: um modo de construir a democracia e a participação. Belo Horizonte: Autêntica, 2004.

VIZER, E. Movimentos sociais: novas tecnologias para as novas militâncias. In: FERREIRA, J.; VIZER, E. (Org.). Mídia e movimentos sociais: linguagens e coletivos em ação. São Paulo: Paulus, 2007. p. 23-52.

Recebido: 07/04/2011

Received: 04/07/2011

Aprovado: 17/10/2011

Approved: 10/17/2011 